NASA/TM-2000-209937

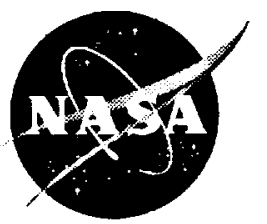

\title{
Prediction of Sound Waves Propagating Through a Nozzle Without/With a Shock Wave Using the Space-Time CE/SE Method
}

Xiao-Yen Wang

Taitech Inc., Cleveland, Ohio

Sin-Chung Chang and Philip C.E. Jorgenson

Glenn Research Center, Cleveland, Ohio 
Since its founding, NASA has been dedicated to the advancement of aeronautics and space science. The NASA Scientific and Technical Information (STI) Program Office plays a key part in helping NASA maintain this important role.

The NASA STI Program Office is operated by Langley Research Center, the Lead Center for NASA's scientific and technical information. The NASA STI Program Office provides access to the NASA STI Database, the largest collection of aeronautical and space science STI in the world. The Program Office is also NASA's institutional mechanism for disseminating the results of its research and development activities. These results are published by NASA in the NASA STI Report Series, which includes the following report types:

- TECHNICAL PUBLICATION. Reports of completed research or a major significant phase of research that present the results of NASA programs and include extensive data or theoretical analysis. Includes compilations of significant scientific and technical data and information deemed to be of continuing reference value. NASA's counterpart of peerreviewed formal professional papers but has less stringent limitations on manuscript length and extent of graphic presentations.

- TECHNICAL MEMORANDUM. Scientific and technical findings that are preliminary or of specialized interest, e.g., quick release reports, working papers, and bibliographies that contain minimal annotation. Does not contain extensive analysis.

- CONTRACTOR REPORT. Scientific and technical findings by NASA-sponsored contractors and grantees.
- CONFERENCE PUBLICATION. Collected papers from scientific and technical conferences, symposia, seminars, or other meetings sponsored or cosponsored by NASA.

- SPECIAL PUBLICATION. Scientific, technical, or historical information from NASA programs, projects, and missions, often concerned with subjects having substantial public interest.

- TECHNICAL TRANSLATION. Englishlanguage translations of foreign scientific and technical material pertinent to NASA's mission.

Specialized services that complement the STI Program Office's diverse offerings include creating custom thesauri, building customized data bases, organizing and publishing research results ... even providing videos.

For more information about the NASA STI Program Office, see the following;

- Access the NASA STI Program Home Page at http://www.sti.nasa.gov

- E-mail your question via the Internet to help@sti.nasa.gov

- Fax your question to the NASA Access Help Desk at (301) 621-0134

- Telephone the NASA Access Help Desk at (301) 621-0390

- Write to: NASA Access Help Desk NASA Center for AeroSpace Information 7121 Standard Drive Hanover, MD 21076 
NASA/TM-2000-209937

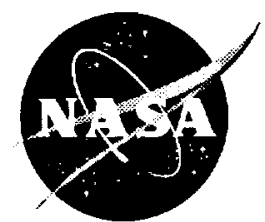

Prediction of Sound Waves Propagating Through a Nozzle Without/With a Shock Wave Using the Space-Time CE/SE Method

Xiao-Yen Wang

Taitech Inc., Cleveland, Ohio

Sin-Chung Chang and Philip C.E. Jorgenson

Glenn Research Center, Cleveland, Ohio

Prepared for the

38th Aerospace Sciences Meeting and Exhibit

sponsored by the American Institute of Aeronautics and Astronautics

Reno, Nevada, January 10-13, 2000

National Aeronautics and

Space Administration

Glenn Research Center 


\section{Acknowledgments}

This work was supported by NASA Glenn Research Center through Contract NAS3-97186. The first author would like thank Dr. Ray Hixon for providing the analytical solutions of both problems.

Available from

NASA Center for Aerospace Information

7121 Standard Drive

Hanover, MD 21076

Price Code: A03
National Technical Information Service 5285 Port Royal Road Springfield, VA 22100

Price Code: A03 


\title{
PREDICTION OF SOUND WAVES PROPAGATING THROUGH A NOZZLE WITHOUT/WITH A SHOCK WAVE USING THE SPACE-TIME CE/SE METHOD
}

\author{
Xiao-Yen Wang* \\ Taitech Inc. \\ Cleveland, $\mathrm{OH} 44135$ \\ Sin-Chung Chang ${ }^{\dagger}$ and Philip C.E. Jorgenson ${ }^{\ddagger}$ \\ NASA Glenn Research Center \\ Cleveland, $\mathrm{OH} 44135$
}

\begin{abstract}
The benchmark problems in Category 1(Internal Propagation) of the third Computational Aeroacoustics (CAA) Workshop sponsored by NASA Glenn Research Center are solved using the space-time conservation element and solution element (CE/SE) method. The first problem addresses the propagation of sound waves through a nearly choked transonic nozzle. The second one concerns shock-sound interaction in a supersonic nozzle. A quasi 1-D $\mathrm{CE} / \mathrm{SE}$ Euler solver for a nonuniform mesh is developed and employed to solve both problems. Numerical solutions are compared with the analytical solution for both problems. It is demonstrated that the $\mathrm{CE} / \mathrm{SE}$ method is capable of solving aeroacoustic problems with/without shock waves in a simple way. Furthermore, the simple non-reflecting boundary condition used in the CE/SE method which is not based on the characteristic theory works very well.
\end{abstract}

\section{Introduction}

The method of space-time conservation element and solution element (abbreviated as the CE/SE method) is an innovative numerical method for solving conservation laws. It is different in both concept and methodology from the well-established traditional methods such as the finite difference, finite volume, finite element and spectral methods. It is designed from a physicist's perspective to overcome several key limitations of the traditional numerical methods.

Simplicity, generality and accuracy are weighted in the development of this method while the fundamental requirements are satisfied by the scheme. Its

\footnotetext{
${ }^{*}$ Research Engineer, Member AIAA

email: wangxy@aem.umn.edu

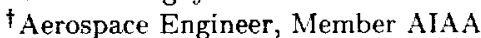

Aerospace Engineer, Member AIAA
}

salient properties are summarized briefly as follow's. First, the concepts of conservation element and solution element are introduced to enforce both local and global flux conservations in space and time instead of in space only. Second, all the dependent variables and their spatial derivatives are considered as individual unknowns to be solved for simultaneously at each grid point. Third, no approximation techniques other than Taylor's series expansion, no monotonicity constraints, and no characteristic-based techniques are used in the design of the scheme. A detailed description of this method and the accompanied analysis can be found in [1-3].

A variety of numerical tests have been performed previously to illustrate the accuracy of this method. For the CE/SE Euler solver, highly accurate numerical solutions have been obtained for various flow problems involving discontinuities, such as shock waves, contact surfaces and even their interactions[4]. Moreover, applications of the same Euler solver to computational aeroacoustics (CAA) problems reveal that the accuracy of the results is comparable to that of a 4 th-order compact difference scheme even though the current solver is only 2ndorder accurate, and the nonreflecting boundary condition can be implemented in a simple way without involving characteristic variables. It can be applied to subsonic, transonic, and supersonic flows in the same form without using the characteristic-based techniques. Results show that the present solver can handle both continuous and discontinuous flows very well[5-11].

In this paper, a quasi 1-D CE/SE Euler solver for a nonuniform mesh is developed and used to solve the benchmark problem in Category 1(Internal Propagation) of the third Computational Aeroacoustics (CAA) Workshop. Among the two proposed problems, one addresses the propagation of sound waves through a transonic nozzle and another concerns shock-sound interaction in a supersonic nozzle. For problem 1, both uniform meshes with constant numerical dissipation models and nonuniform 
meshes with variable numerical dissipation models are used. Numerical results are presented and compared with the analytical solution. A good agreement is achieved by using a stretched 401 point mesh. For problem 2, 101 and 201 point uniform meshes are used and excellent agreements with the analytical solution are obtained. Further, the numerical solutions obtained by solving the linearized equations are compared with those obtained by solving the nonlinear equations for both problems.

\section{Governing Equations and Numerical Schemes}

In the following, the nonlinear quasi 1D Euler equations are described in conservative form first, which is followed by numerical schemes, numerical results and conclusions.

\subsection{Governing Equations}

The quasi 1-D Euler equations in conservative form are expressed as

$$
\frac{\partial u_{m}}{\partial t}+\frac{\partial f_{m}}{\partial x}=g_{m}, \quad m=1,2,3
$$

in which

$$
u_{1}=\rho, \quad u_{2}=\rho v, \quad u_{3}=p /(\gamma-1)+\rho v^{2} / 2
$$

and

$$
\begin{gathered}
f_{1}=u_{2} \\
f_{2}=(\gamma-1) u_{3}+(3-\gamma)\left(u_{2}\right)^{2} /\left(2 u_{1}\right) \\
f_{3}=\gamma u_{2} u_{3} / u_{1}-(1 / 2)(\gamma-1)\left(u_{2}\right)^{3} /\left(u_{1}\right)^{2} \\
g_{1}=-u_{2} \frac{\partial A}{\partial x} \frac{1}{A} \\
g_{2}=-\left(u_{2}\right)^{2} / u_{1} \frac{\partial A}{\partial x} \frac{1}{A} \\
g_{3}=-f_{3} \frac{\partial A}{\partial x} \frac{1}{A}
\end{gathered}
$$

where $\rho, v, p$, and $\gamma$ are the mass density, velocity, static pressure, and constant specific heat ratio, respectively, and $A$ is the area of a nozzle.

Let $x_{1}=x$ and $x_{2}=t$ be the coordinates of a two-dimensional Euclidean space, $E_{2}$. The integral form of Eq. (1) in space-time $E_{2}$ is

$$
\oint_{S(V)} \vec{h}_{m} \cdot d \vec{s}=\iint_{V} g_{m} d v, \quad m=1,2,3
$$

where (i) $S(V)$ is the boundary of an arbitrary spacetime region $V$ in $E_{2}$; (ii) $\vec{h}_{m}=\left(f_{m}, u_{m}\right), m=1,2,3$, are the space-time mass, momentum, and energy flux vectors, respectively; (iii) $d \vec{s}=d \sigma \vec{n}$ with $d \sigma$ and $\vec{n}$, respectively, being the area and the outward unit normal of a surface element on $S(V)$; and (iv) $d v$ is the volume of the space-time region $V$. Note that (i) $\vec{h}_{m} \cdot d \vec{s}$ is the space-time flux of $\vec{h}_{m}$ leaving the region $V$ through the surface element $d \vec{s}$; (ii) $\iint_{V} g_{m} d v$ is the volume integration of the source term $g_{m}$ over the space-time region $\mathrm{V}$; and (iii) all mathematical operations can be carried out as though $E_{2}$ were an ordinary two-dimensional Euclidean space.

As a preliminary, let

$$
f_{m, l}=\partial f_{m} / \partial u_{l}, \quad m, l=1,2,3 .
$$

The Jacobian matrix $F$, which is formed by $f_{m, l}, m, l=1,2,3$, is referred to in [1].

Because $f_{m}, m=1,2,3$ are homogeneous functions of degree one in $u_{1}, u_{2}$, and $u_{3}$, we have

$$
f_{m}=\sum_{l=1}^{3} f_{m, l} u_{l} .
$$

\subsection{The 1D Space-Time Nonuniform Mesh}

Consider a nonuniform mesh shown in Fig. 1, in which the solid circles are the grid points and crosses are the solution points. Assume the spatial coordinate of the grid points be $x_{j}$ with $j=$ $0,1 / 2,1,3 / 2,2,5 / 2$. Generally, the grid point $j$ is not the centroid of the line formed by grid points $j+1 / 2$ and $j-1 / 2$. Let $x_{j}^{\prime}$ denote the spatial coordinate of the solution points. Define

$$
x_{j}^{\prime}=\left(x_{j-1 / 2}+x_{j+1 / 2}\right) / 2
$$

for interior mesh points, while $x_{j}^{\prime}=x_{j}$ for boundary points.

The definitions of the conservation element(CE) and solution element(SE) at a grid point $j$ are the same as those for $1 \mathrm{D}$ uniform mesh in [1]. The flow marching variables are computed at the solution points, while the grid points are used to construct CEs and SEs. For later use, we define

$$
\begin{aligned}
& \Delta x_{j}^{-} \stackrel{\text { def }}{=} x_{j}-x_{j-1 / 2} \\
& \Delta x_{j}^{+} \stackrel{\text { def }}{=} x_{j+1 / 2}-x_{j}
\end{aligned}
$$

and

$$
\Delta x_{j} \stackrel{\text { def }}{=} x_{j+1 / 2}-x_{j-1 / 2} \text {. }
$$

\subsection{The Quasi 1D Euler $a$ Scheme}

For any $(x, t) \in \mathrm{SE}(j, n), u_{m}(x, t), f_{m}(x, t)$, and $\vec{h}_{m}(x, t)$ are approximated by $u_{m}^{*}(x, t ; j, n)$, 
$f_{m}^{*}(x, t ; j, n)$, and $\vec{h}_{m}^{*}(x, t ; j, n)$, respectively. They will be defined shortly. Let

$u_{m}^{*}(x, t ; j, n) \stackrel{\text { def }}{=}\left(u_{m}\right)_{j}^{n}+\left(u_{m x}\right)_{j}^{n}\left(x-x_{j}^{\prime}\right)+\left(u_{m t}\right)_{j}^{n}\left(t-t^{n}\right)$

where $\left(u_{m}\right)_{j}^{n},\left(u_{m x}\right)_{j}^{n}$, and $\left(u_{m t}\right)_{j}^{n}$ are constant within $\operatorname{SE}(j, n)$. Obviously, they can be considered as the numerical analogues of the values of $u_{m}, \partial u_{m} / \partial x$, and $\partial u_{m} / \partial t$ at $\left(x_{j}^{\prime}, t^{n}\right)$, respectively.

Let $\left(f_{m}\right)_{j}^{n}$ and $\left(f_{m, l}\right)_{j}^{n}$ denote the values of $f_{m}$ and $f_{m, l}$, respectively, when $u_{m}, m=1,2,3$, respectively, assume the values of $\left(u_{m}\right)_{j}^{n}, m=1,2,3$. For any $m=1,2,3$, let

$$
\left(f_{m x}\right)_{j}^{n}=\sum_{l=1}^{3}\left(f_{m, l}\right)_{j}^{n}\left(u_{l x}\right)_{j}^{n}
$$

and

$$
\left(f_{m t}\right)_{j}^{n}=\sum_{l=1}^{3}\left(f_{m, l}\right)_{j}^{n}\left(u_{l t}\right)_{j}^{n}
$$

Because

$$
\frac{\partial f_{m}}{\partial t}=\sum_{\ell=1}^{3} f_{m, \ell} \frac{\partial u_{\ell}}{\partial t}
$$

and

$$
\frac{\partial f_{m}}{\partial x}=\sum_{\ell=1}^{3} f_{m, \ell} \frac{\partial u_{\ell}}{\partial x}
$$

$\left(f_{m x}\right)_{j}^{n}$ and $\left(f_{m t}\right)_{j}^{n}$ can be considered as the numerical analogues of the values of $\partial f_{m} / \partial x$, and $\partial f_{m} / \partial t$ at $\left(x_{j}^{\prime}, t^{n}\right)$, respectively. As a result, we define

$f_{m}^{*}(x, t ; j, n) \stackrel{\text { def }}{=}\left(f_{m}\right)_{j}^{n}+\left(f_{m x}\right)_{j}^{n}\left(x-x_{j}^{\prime}\right)+\left(f_{m t}\right)_{j}^{n}\left(t-t^{n}\right)$

Because $\vec{h}_{m}=\left(f_{m}, u_{m}\right)$, we also assume that

$$
\vec{h}_{m}^{*}(x, t ; j, n)=\left(f_{m}^{*}(x, t ; j, n), u_{m}^{*}(x, t ; j, n)\right)
$$

Note that, by their definitions: (i) $\left(f_{m}\right)_{j}^{n},\left(f_{m, l}^{x}\right)_{j}^{n}$ are functions of $\left(u_{m}\right)_{j}^{n}, m=1,2,3$; (ii) $\left(f_{m x}\right)_{j}^{n}$ are functions of $\left(u_{m}\right)_{j}^{n}$ and $\left(u_{m x}\right)_{j}^{n}, m=1,2,3$; and (iii) $\left(f_{m t}\right)_{j}^{n}$ are functions of $\left(u_{m}\right)_{j}^{n}$ and $\left(u_{m t}\right)_{j}^{n}, m=$ $1,2,3$.

Moreover, we assume that for any $(x, t) \in \operatorname{SE}(j, n)$, and for $m=1,2,3$,

$$
\frac{\partial u_{m}^{*}(x, t ; j, n)}{\partial t}+\frac{\partial f_{m}^{*}(x, t ; j, n)}{\partial x}=\left(g_{m}\right)_{j}^{n} .
$$

Note that Eq. (23) is the numerical analogue of Eq. (1). With the aid of Eqs. (16) and (21), Eq. (23) implies that, for any $m=1,2,3$,

$$
\begin{aligned}
\left(u_{m t}\right)_{j}^{n} & =-\left(f_{m x}\right)_{j}^{n}+\left(g_{m}\right)_{j}^{n} \\
& =-\sum_{l=1}^{3}\left[f_{m, l}^{x} u_{l x}\right]_{j}^{n}+\left(g_{m}\right)_{j}^{n}
\end{aligned}
$$

Since $\left(g_{m}\right)_{j}^{n}$ is also a function of $\left(u_{m}\right)_{j}^{n}, m=1,2,3$, thus $\left(u_{m t}\right)_{j}^{n}$ is a function of $\left(u_{m}\right)_{j}^{n}$ and $\left(u_{m x}\right)_{j}^{n}$. From this result and the facts stated following Eq. (22), one concludes that, for each $m=1,2,3$, there are only two independent discrete variables, i.e., $\left(u_{m}\right)_{j}^{n}$, $\left(u_{m x}\right)_{j}^{n}$, associated with the mesh point $(j, n)$.

Further, the flux $\vec{h}_{m}^{*}$ is conserved over $\mathrm{CE}_{ \pm}(j, n)$, i.e.,

$\oint_{S\left(C E_{-}(j, n)\right)} \vec{h}_{m}^{*} \cdot d \vec{s}=\left[\left(g_{m}\right)_{j-1 / 2}^{n-1 / 2}+\left(g_{m}\right)_{j}^{n}\right] \frac{\Delta t \Delta x_{j}^{-}}{4}$

and

$\oint_{S\left(C E_{+}(j, n)\right)} \vec{h}_{m}^{*} \cdot d \vec{s}=\left[\left(g_{m}\right)_{j+1 / 2}^{n-1 / 2}+\left(g_{m}\right)_{j}^{n}\right] \frac{\Delta t \Delta x_{j}^{+}}{4}$

where $S\left(C E_{ \pm}(j, n)\right)$ denotes the boundary of $C E_{ \pm}(j, n)$. Note that Eqs. (25) and (26) are the numerical analogues of Eq. (9).

Let $\vec{u}_{j}^{n},\left(\vec{u}_{x}\right)_{j}^{n}$ and $\vec{g}_{j}^{n}$, respectively, be the $3 \times 1$ column matrices formed by $\left(u_{m}\right)_{j}^{n},\left(u_{m x}\right)_{j}^{n}$ and $\left(g_{m}\right)_{j}^{n}, m=1,2,3$. Let $F_{j}^{n}$ denote the $3 \times 3$ Jacobian matrices formed by $\left(f_{m, l}\right)_{j}^{n}, m, l=1,2,3$. Define

$$
\begin{gathered}
\left(F^{+}\right)_{j}^{n} \stackrel{\text { def }}{=} \frac{\Delta t}{4} F_{j}^{n} \\
\left(\vec{g}^{+}\right)_{j}^{n} \stackrel{\text { def }}{=} \frac{\Delta t}{4} \vec{g}_{j}^{n}
\end{gathered}
$$

With the above preparations, a new set of $3 \times 3$ matrices will be defined at each mesh point $(j, n)$. To simplify notation, we will strip from all $3 \times 3$ matrices involved, their indices $j$ and $n$. Define

$$
\begin{array}{lll}
\Sigma_{11}^{+} & \stackrel{\text { def }}{=} & \Delta x_{j}^{-} I+2 F^{+} \\
\Sigma_{12}^{+} & \stackrel{\text { def }}{=} \Delta x_{j}^{-}\left(\frac{x_{j-1 / 2}+x_{j}}{2}-x_{j}^{\prime}\right) I+ \\
& 2\left(F^{+}\right)^{2} \\
\Sigma_{11}^{-} & \stackrel{\text { def }}{=} \Delta x_{j}^{-} I+2 F^{+} \\
\Sigma_{12}^{-} \stackrel{\text { def }}{=} \Delta x_{j}^{-}\left(\frac{x_{j-1 / 2}+x_{j}}{2}-x_{j-1 / 2}^{\prime}\right) I- & \\
\Sigma_{21}^{+} \stackrel{\text { def }}{=} \Delta x_{j}^{+} I-2 F^{+} \\
\Sigma_{22}^{+} \stackrel{\text { def }}{=} \Delta x_{j}^{+}\left(\frac{x_{j+1 / 2}+x_{j}}{2}-x_{j}^{\prime}\right) I- \\
\Sigma_{21}^{-} \stackrel{\text { def }}{=} \Delta x_{j}^{+} I-2 F^{+} \\
\Sigma_{22}^{-} \stackrel{\text { def }}{=} \Delta x_{j}^{+}\left(\frac{x_{j+1 / 2}+x_{j}}{2}-x_{j+1 / 2}^{\prime}\right) I+ \\
& 2\left(F^{+}\right)^{2}
\end{array}
$$


where $I$ is the $3 \times 3$ identity matrix.

Note that, with the aid of Eqs. (12)-(15), it can be shown that

$$
\begin{gathered}
\Sigma_{11}^{+}+\Sigma_{21}^{+}=\Delta x_{j} I \\
\Sigma_{12}^{+}+\Sigma_{22}^{+}=0
\end{gathered}
$$

Next we will show how to compute Eqs. (25) and (26). Because $u_{m}^{*}(x, t ; j, n)$ is linear in $x$ and $t$, the total flux of $\vec{h}_{m}^{*}$ leaving $\mathrm{CE}_{ \pm}(j, n)$ through any one of the line segments that form its boundary is equal to the scalar product of the vector $\vec{h}_{m}^{*}$ evaluated at the centroid of the line, and the normal vector of the line. The results of this evaluation can be combined into the matrix form

$$
\begin{array}{r}
{\left[\Sigma_{11}^{+}\left(\vec{u}-\vec{g}^{+}\right)+\Sigma_{12}^{+} \vec{u}_{x}\right]_{j}^{n}} \\
{\left[\Sigma_{11}^{-}\left(\vec{u}+\vec{g}^{+}\right)+\Sigma_{12}^{-} \vec{u}_{x}\right]_{j-1 / 2}^{n-1 / 2}}
\end{array}
$$

and

$$
\begin{gathered}
{\left[\Sigma_{21}^{+}\left(\vec{u}-\vec{g}^{+}\right)+\Sigma_{22}^{+} \vec{u}_{x}\right]_{j}^{n}=} \\
{\left[\Sigma_{21}^{-}\left(\vec{u}+\vec{g}^{+}\right)+\Sigma_{22}^{-} \vec{u}_{x}\right]_{j+1 / 2}^{n-1 / 2} .}
\end{gathered}
$$

$\mathrm{By}$ adding the two matrix equations and using Eqs. (37) and (38), one concludes that

$$
\begin{gathered}
\left(\vec{u}-\vec{g}^{+}\right)_{j}^{n}=\frac{1}{\Delta x_{j}}\left\{\left[\Sigma_{11}^{-}\left(\vec{u}+\vec{g}^{+}\right)+\Sigma_{12}^{-} \vec{u}_{x}\right]_{j-1 / 2}^{n-1 / 2}\right. \\
\left.\left[\Sigma_{21}^{-}\left(\vec{u}+\vec{g}^{+}\right)+\Sigma_{22}^{-} \vec{u}_{x}\right]_{j+1 / 2}^{n-1 / 2}\right\}
\end{gathered}
$$

i.e., $\vec{u}_{j}^{n}$ can be obtained using an iterative method, such as Newton iterative method, in terms of the marching variables at the $(n-1 / 2)$ th time level. Furthermore, it can be seen that the matrices $\left(\Sigma_{r s}^{+}\right)_{j}^{n}, r, s=1,2$ and $\left(\vec{g}^{+}\right)_{j}^{n}$, are functions of $\vec{u}_{j}^{n}$ only, they become known once $\vec{u}_{j}^{n}$ is known. Thus $\left(\vec{u}_{x}\right)_{j}^{n}$ can be computed using either Eq. (39) or (40). Consider Eq. (39) for an example. Define

$\left(\vec{S}_{1}\right)_{j}^{n} \stackrel{\text { def }}{=}\left[\Sigma_{11}^{-}\left(\vec{u}+\vec{g}^{+}\right)+\Sigma_{12}^{-} \vec{u}_{x}\right]_{j-1 / 2}^{n-1 / 2}-\left[\Sigma_{11}^{+}\left(\vec{u}-\vec{g}^{+}\right)\right]_{j}^{n}$.

Then Eq. (39) can be rewritten as

$$
\left[\Sigma_{12}^{+} \vec{u}_{x}\right]_{j}^{n}=\left(\vec{S}_{1}\right)_{j}^{n}
$$

With assumption that $\left[\left(\Sigma_{12}^{+}\right)_{j}^{n}\right]^{-1}$ exists, we can have

$$
\left(\vec{u}_{x}\right)_{j}^{n}=\left[\left(\Sigma_{12}^{+}\right)_{j}^{n}\right]^{-1}\left(\vec{S}_{1}\right)_{j}^{n} .
$$

Note that $\left(\vec{u}_{x}\right)_{j}^{n}$ can be computed in the similar way using Eq. (40). Let $\left(\vec{u}_{x}^{a}\right)_{j}^{n}$ denote the solution. Then the 2D CE/SE Euler $a$ scheme is formed by Eq. (41) and

$$
\left(\vec{u}_{x}\right)_{j}^{n}=\left(\vec{u}_{x}^{a}\right)_{j}^{n}
$$

\subsection{The Quasi 1D Euler $a-\epsilon-\alpha-\beta$ Scheme}

The quasi 1D CE/SE Euler $a-\epsilon-\alpha-\beta$ scheme for a nonuniform mesh can be derived in the same way as that for $1 \mathrm{D} \mathrm{CE} / \mathrm{SE}$ Euler $a-\epsilon-\alpha-\beta$ scheme for a uniform mesh.

Let

$$
\left(u_{m}^{\prime}\right)_{j \pm 1 / 2}^{n}=\left(u_{m}\right)_{j \pm 1 / 2}^{n-1 / 2}+(\Delta t) / 2\left(u_{m t}\right)_{j \pm 1 / 2}^{n-1 / 2}
$$

and define

$$
\begin{aligned}
& \left(u_{m x-}^{c}\right)_{j}^{n} \stackrel{\text { def }}{=}\left[\left(u_{m}\right)_{j}^{n}-\left(u_{m}^{r}\right)_{j-1 / 2}^{n}\right] / \Delta x_{j}^{-} \\
& \left(u_{m x+}^{c}\right)_{j}^{n} \stackrel{\text { def }}{=}\left[\left(u_{m}^{\prime}\right)_{j+1 / 2}^{n}-\left(u_{m}\right)_{j}^{n}\right] / \Delta x_{j}^{+}
\end{aligned}
$$

and

$$
\left(u_{m x}^{c}\right)_{j}^{n} \stackrel{\text { def }}{=}\left[\left(u_{m}^{\prime}\right)_{j+1 / 2}^{n}-\left(u_{m}^{\prime}\right)_{j-1 / 2}^{n}\right] / \Delta x_{j} .
$$

Further, we can define

$$
u_{m x}^{w}=\frac{\left|u_{m x-}^{c}\right|^{\alpha} u_{m x+}^{c}+\left|u_{m x+}^{c}\right|^{\alpha} u_{m x-}^{c}}{\left|u_{m x-}^{c}\right|^{\alpha}+\left|u_{m x+}^{c}\right|^{\alpha}}
$$

for $\left|u_{m x-}^{c}\right|^{a}+\left|u_{m x+}^{c}\right|^{\alpha}>0$, otherwise $u_{m x}^{w}=0$.

The quasi 1D CE/SE Euler $a-\epsilon-\alpha-\beta$ scheme is formed by Eq. (41) and

$\left(\vec{u}_{x}\right)_{j}^{n}=\left(\vec{u}_{x}^{a}\right)_{j}^{n}+2 \epsilon\left(\left(\vec{u}_{x}^{c}\right)_{j}^{n}-\left(\vec{u}_{x}^{a}\right)_{j}^{n}\right)+\beta\left(\left(\vec{u}_{x}^{w}\right)_{j}^{n}-\left(\vec{u}_{x}^{c}\right)_{j}^{n}\right)$

where $\epsilon, \alpha$ and $\beta$ are parameters for controlling numerical dissipations. They can be either constants or variables. With $\epsilon, \alpha$ and $\beta$ being held constant, numerical dissipation associated with the present scheme at a mesh point $(j, n)$ tends to increase as the local Courant number $\nu_{j}^{n}$ decreases. To compensate for this effect, $\epsilon$ and $\beta$ in Eq. (51) may be replaced by $\epsilon\left(\nu_{j}^{n}\right)$ and $\beta\left(\nu_{j}^{n}\right)$ which are expressed as

$$
\begin{gathered}
\epsilon\left(\nu_{j}^{n}\right)=0.5 \nu_{j}^{n} \exp \left(1-\nu_{j}^{n}\right) \quad \text { and } \\
\beta\left(\nu_{j}^{n}\right)=\sqrt{\nu_{j}^{n}}, \quad 0 \leq \nu_{j}^{n} \leq 1 .
\end{gathered}
$$

Note that $\epsilon\left(\nu_{j}^{n}\right)$ and $\beta\left(\nu_{j}^{n}\right)$, are monotonically increasing function of $\nu_{j}^{n}$ with $\epsilon(0)=0$ and $\beta(0)=0$. A 1D CE/SE Euler solver with $\epsilon\left(\nu_{j}^{n}\right)$ and $\beta\left(\nu_{j}^{n}\right)$ in Eq. (52) was used in [1] to obtain accurate shock tube solutions with the maximal Courant number in each numerical simulation ranging from 0.88 to 0.022 .

Similarly, the quasi 1D CE/SE Euler solver is second-order accurate in both space and time. The 
stability condition is the Courant number less than unity.

\section{Numerical Results}

For the two problems solved in the following, the CE/SE quasi 1D Euler solver described previously for the nonlinear equations is used to compute the steady-state solution of the nozzle flowfield. For the simulation of acoustic wave propagation, both the linear and nonlinear quasi 1D Euler solvers are used under the same computational conditions. The linear solver is constructed for the linearized quasi 1D Euler equations in conservative form. It has the identical formulation as the nonlinear solver except the time-marching variables are different. The details of the linear solver will be described in a separate paper. Both the linear and nonlinear numerical solutions are presented. Numerical solutions of the acoustic wave plotted in all figures are nondimensionalized by its amplitude $\varepsilon$. In the computations using a uniform mesh, the constant numerical dissipation model with $\epsilon=0.2, \alpha=0$, and $\beta=1$ is used for both problems.

\subsection{Propagation of Sound Waves through a Transonic Nozzle}

The first problem addresses propagation of sound waves in a transonic nozzle, in which the local Mach number of flow near the throat may be close to sonic. The computation of sound propagating through such regions presents a challenging problem. The area of the nozzle is

$$
\begin{aligned}
& A(x)= \\
& \left\{\begin{array}{l}
0.536572-0.198086 \exp \left(-(\ln 2)\left(\frac{x}{0.6}\right)^{2}\right), x>0 \\
1.0-0.661514 \exp \left(-(\ln 2)\left(\frac{x}{0.6}\right)^{2}\right), x<0 .
\end{array}\right.
\end{aligned}
$$

In the uniform region downstream of the throat, the diameter of the nozzle is $D$ and the main flow is uniform with Mach number, $M_{\infty}$, of 0.4 , speed of sound, $a_{\infty}$, and static density, $\rho_{\infty}$. Flow variables are non-dimensionalized by using $a_{\infty}$ as the velocity scale, $D$ as the length scale, $D / a_{\infty}$ as the time scale, $\rho_{\infty}$ as the density scale, and $\rho_{\infty} a_{\infty}^{2}$ as the pressure scale. Thus the mean flow in the uniform region downstream of the throat is

$$
\rho=1, \quad v=0.4, \quad p=1 / 1.4 .
$$

The acoustic wave, with angular frequency $\omega=0.6 \pi$, is described as

$$
\rho^{\prime}=p^{\prime}=\varepsilon \cos \left[\omega\left(\frac{x}{1-M_{\infty}}+t\right)\right],
$$

$$
v^{\prime}=-\varepsilon \cos \left[\omega\left(\frac{x}{1-M_{\infty}}+t\right)\right]
$$

where $\varepsilon=10^{-4}$. It is generated downstream and propagates upstream through the narrow passage of the nozzle throat. The computational domain is $-10 \leq x \leq 10$. It is recommended that computations use no more than 400 mesh intervals.

As the first step, the steady-state solution of the nozzle flow is computed. The initial conditions are specified using flow properties in the uniform downstream region. For imposing the boundary conditions, the back pressure $\left(p_{b a c k}=1 / 1.4\right)$ is specified at the outlet, and the total pressure and total density are specified at the inlet. The other needed information at both the inlet and outlet are obtained using extrapolation from their neighboring mesh points. The steady-state solution obtained using a 401 point uniform mesh with $C F L=0.847$ is shown in Fig. 2 in comparison with the exact solution represented by solid lines. It can be seen that flow properties are uniform in most region of the nozzle, but change dramatically near the nozzle throat.

After the steady-state nozzle flowfield is available, the acoustic wave propagation can be simulated using the same nonlinear Euler solver. The initial conditions are specified using the steady-state solution of nozzle flowfield. The boundary condition is different from that used for computing the steady-state solution. At the outlet, the time-marching variables are specified as

$$
\begin{gathered}
\left(u_{1}\right)_{j}^{n}=\rho+\rho^{\prime} \\
\left(u_{2}\right)_{j}^{n}=\left(\rho+\rho^{\prime}\right)\left(v+v^{\prime}\right) \\
\left(u_{3}\right)_{j}^{n}=\frac{p+p^{\prime}}{\gamma-1}+\frac{1}{2}\left(\rho+\rho^{\prime}\right)\left(v+v^{\prime}\right)^{2} .
\end{gathered}
$$

At the inlet, the non-reflecting boundary condition is enforced by setting

$$
\left(u_{m}\right)_{j}^{n+1 / 2}=\left(u_{m}\right)_{j+1 / 2}^{n}, \quad\left(u_{m x}\right)_{j}^{n+1 / 2}=0
$$

where $m=1,2,3$.

Different mesh sizes are tested in the current computation. First, uniform meshes with $\Delta x=0.05$ and 0.025 in the computational domain of $-10 \leq x \leq 10$ are used. Numerical solutions of the acoustic pressure $p^{t}$ at $t=20 T$ are shown in Figs. 3 and 4, respectively and compared with the analytical solution. It can be seen that the peak values near the throat and wave pattern upstream of the throat can not be captured correctly using a 401 point uniform mesh, while a greatly improved result is produced using an 801 point uniform mesh. The amplitude of the acoustic wave upstream of the throat is lower than 
that given by the analytical solution. Further, the corresponding solutions obtained with $\Delta x=0.0125$ in the computational domain of $-5 \leq x \leq 5$ are shown in Fig. 5. Although the peak values are still not the same as the analytical solution, the profiles of the $p^{\prime}$ both upstream and downstream of the throat agree very well with the analytical solution.

In order to reduce the number of grid points, a 401 point nonuniform mesh that cluster near the throat is used. The ratio of the largest to smallest mesh interval is around 10 with $\Delta x_{\min }=0.0047$. The variable $\epsilon_{j}^{n}$ and $\beta_{j}^{n}$ described in Eq. (52), and constant $\alpha=0$ are used in the computation. The obtained acoustic pressure at $t=20 T$ with $C F L=0.9084$ is shown in Fig. 6 which is nearly similar to that obtained using an 801 point uniform mesh in the domain of $-10 \leq x \leq 10$. Further improvement can be made in the future by reducing the numerical dissipations or using a more stretched mesh. Its convergence to the time-period solution is shown in Fig. 7 . Under the same computational conditions and mesh, the corresponding solution obtained using $\varepsilon=10^{-3}$ is plotted in Fig. 8 showing skewness upstream of the throat. It can be concluded that the amplitude of the acoustic wave should be small enough to avoid the nonlinearity when a nonlinear scheme is used to obtain the linear solution. In the present computation using a nonlinear solver, the steady-state solutions converge to $10^{-7}$, and $\varepsilon=10^{-4}$ is used.

For the linear solver, the amplitude of the acoustic wave is set to 1 and the steady-state solution obtained by using the nonlinear solver is used in the computation. All the three uniform meshes used for the nonlinear solver described above are tested with the linear solver. The linear solutions are very similar to the nonlinear solutions. The solution obtained using an 801 point uniform mesh in the domain of $-10 \leq x \leq 10$ is shown in Fig. 9 as an example. The nonlinear solution is slightly better than the linear solution under the same computational conditions.

\subsection{Shock-Sound Interaction}

In this problem, the same nozzle geometry from the previous problem is used, but here there is a supersonic shock downstream of the throat. All quantities are non-dimensionalized using the upstream values. The Mach number at the inlet, $M_{\infty}$, is 0.2006533 and the back pressure, $p_{b a c k}$, is 0.6071752 . Following the same steps described in the first problem, the steady-state nozzle flowfield is computed and used as the initial condition for the sound-shock interaction simulation. The acoustic wave is described as

$$
\rho^{\prime}=p^{\prime}=v^{\prime}=\varepsilon \sin \left[\omega\left(\frac{x}{1+M_{\infty}}+t\right)\right]
$$

where $\varepsilon$ and $\omega$ have the same values as that in the first problem. At the inlet, the time-marching variables are specified using Eqs. (56)-(58), while at the outlet, for $m=1,2,3$,

$$
\left(u_{m}\right)_{j}^{n+1 / 2}=\left(u_{m}\right)_{j-1 / 2}^{n}, \quad\left(u_{m x}\right)_{j}^{n+1 / 2}=0
$$

are used as the non-reflecting boundary conditions.

Uniform meshes with 101 and 201 grid points are used for this problem. The steady-state solution obtained using a 101 point uniform mesh is shown in Fig. 10 and compared with the analytical solution represented by solid lines. Numerical solutions of the acoustic wave obtained using 101 and 201 point uniform meshes are shown in Fig. 11, in which only the analytical solution of $p^{\prime}$ is plotted for a comparison. The analytical solutions of the density and velocity are not available. It can be seen that the solution obtained on a 101 point uniform mesh is very close to the analytical solution and that obtained on a 201 point uniform mesh appears to graphically match the analytical solution. A very solid convergence to the time-period solution is demonstrated in Fig. 12 for the coarse mesh. Further, the acoustic pressure at the outlet in one time period is plotted in Fig. 13 along with the analytical solution showing an excellent agreement. The linear solution is almost identical to the nonlinear solution which is shown in Fig. 14 for a 101 point uniform mesh.

\section{Conclusions}

The quasi 1-D CE/SE Euler solver for a nonuniform mesh is developed and applied to simulate the propagation of sound waves and shock-sound interaction in a nozzle. For problem 1, a satisfactory numerical result is obtained using a nonuniform mesh with 401 grid points. For problem 2, an excellent agreement between the numerical results obtained on a 101 point uniform mesh and the analytical solution is achieved. It is demonstrated that the CE/SE method is capable of solving aeroacoustic problems with/without shock waves in a simple way. No special techniques are used for shock waves, and acoustics waves and shock waves can be captured concurrently within the computational domain.

\section{Acknowledgments}

This work was supported by NASA Glenn Research Center through Contract NAS3-97186. The first author would like thank Dr. Ray Hixon for providing the analytical solutions of both problems. 


\section{References}

[1] S.C. Chang, "The Method of Space-Time Conservation Element and Solution Element - A New Approach for Solving the Navier-Stokes and Euler Equations", J. Comput. Phys., 119, pp. 295-324, (1995).

[2] S.C. Chang, X.Y. Wang, and C.Y. Chow, "The Space-Time Conservation Element and Solution Element Method - A New High-Resolution and Genuinely Multidimensional Paradigm for Solving Conservation Laws", J. Comput. Phys., 156, pp. 89-136, (1999).

[3] X.Y. Wang and S.C. Chang, "A 2D Nonsplitting Unstructured-triangular-mesh Euler Solver based on the Method of Space-Time Conservation Element and Solution Element", Vol. 8, No. 2, pp. 326-340, 1999, Computational Fluid Dynamics JOURNAL.

[4] S.C. Chang, C.Y. Loh and S.T. Yu, "Computational Aeroacoustics via a New Global Conservation Scheme", Proceedings of the 15th International Conference on Numerical Methods in Fluid Dynamics, P. Kutler, J. Flores and J.-J. Chat tot, eds., June 24-28, 1996, Monterey, CA.

[5] S.C. Chang, A. Himansu, C.Y. Loh, X.Y. Wang, S.T. Yu and P.C.E. Jorgenson, "Robust and Simple Non-Reflecting Boundary Conditions for the Space-Time Conservation Element and Solution Element Method", AIAA Paper 97-2077, presented at the 13th AIAA CFD Conference, June 29-July 2, 1997, Snowmass, CO.

[6] C.Y. Loh, S.C. Chang, J.R. Scott and S.T. Yu, "Application of the Method of Space-Time Conservation Element and Solution Element to Aeroacoustics Problems", A Collection of Technical Papers, Volume II, pp. 713-718, 6th International Symposium on Computational Fluid Dynamics, September 4-8, 1995, Lake Tahoe, NV.
[7] C.Y. Loh, S.C. Chang, J.R. Scott and S.T. Yu, "The Space-Time Conservation Element Method - A New Numerical Scheme for Computational Aeroacoustics", AIAA Paper 960276, presented at the 34 th AIAA Acrospace Sciences Meeting, January 15-18, 1996, Reno, NV.

[8] C.Y. Loh, S.C. Chang and J.R. Scott, "Computational Aeroacoustics via the Space-Time Conservation Element / Solution Element Method", AIAA Paper 96-1687, presented at the 2nd AIAA/CEAS Aeroacoustics Conference, May 6-8, 1996, State College, PA.

[9] C.Y. Loh, L.S. Hultgren and S.C. Chang, "Computing Waves in Compressible Flow Using the Space-Time Conservation Element and Solution Element method," AIAA Paper 98-0369, presented at the 36 th AIAA Aerospace Sciences Meeting, January 12-15, 1998, Reno, NV.

[10] X.Y. Wang, C.Y. Chow and S.C. Chang, "Numerical Simulation of Gust Generated Aeroacoustics in a Cascade Using the Space-Time Conservation Element and Solution Element Method," AIAA Paper 98-0178, presented at the 36th AIAA Aerospace Sciences Meeting, January 12-15, 1998, Reno, NV.

[11] X.Y. Wang, C.Y. Chow and S.C. Chang, "Nonreflecting Boundary Conditions Based on the Space-Time CE/SE Method for Free Shear Flows," AIAA paper 98-3020, presented at the 29th AIAA Fluid Dynamics Conference, Albuquerque, New Mexico, June 15-18, 1998. 


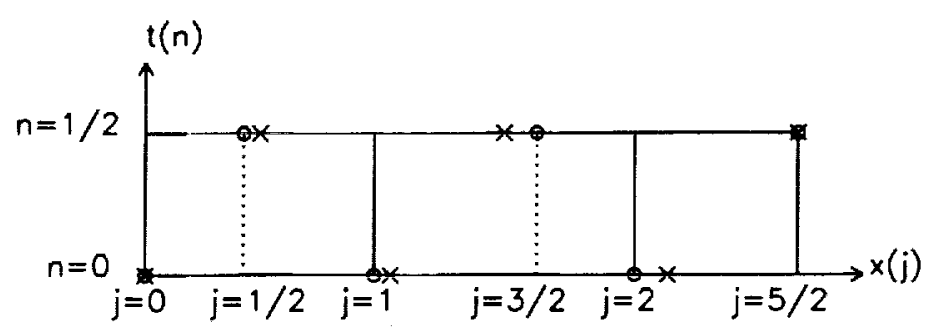

Figure 1: A nonuniform staggered mesh in the spacetime domain.

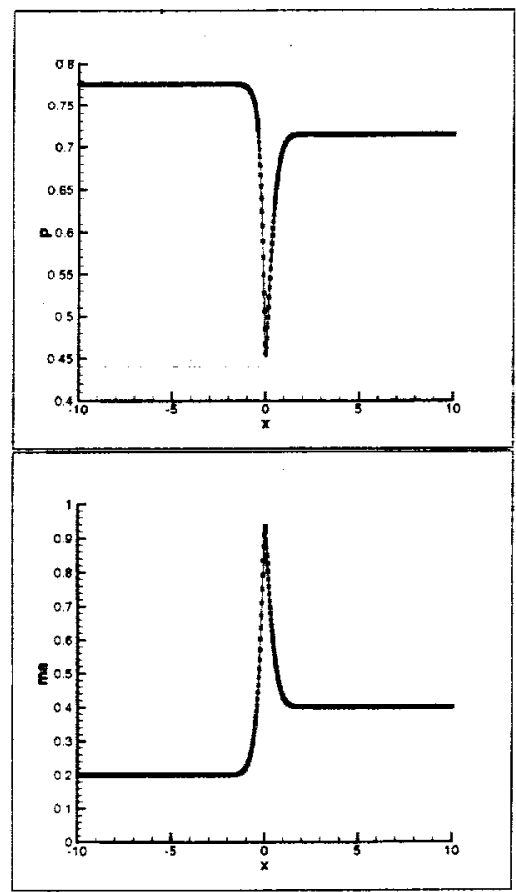

Figure 2: The steady-state solution(401 point uniform mesh) of the nozzle flowfield compared with the exact solution represented by solid lines.

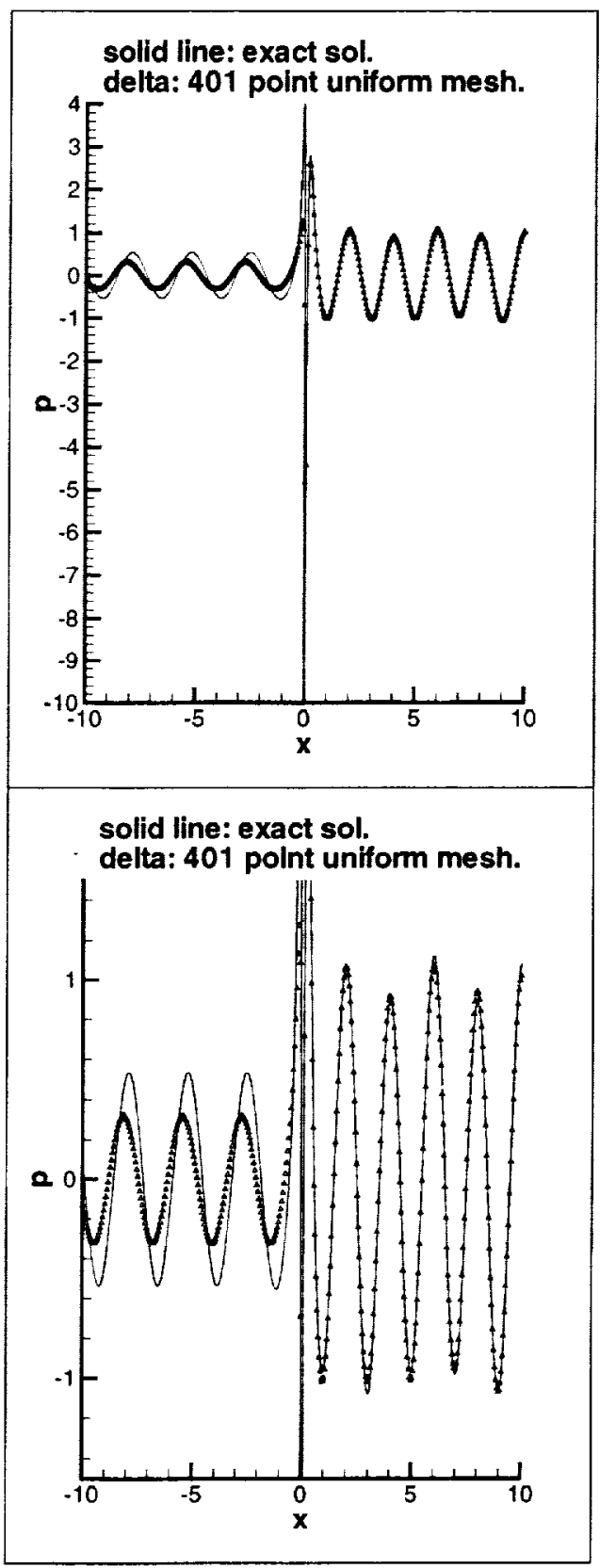

Figure 3: Comparisons between the exact solution and $\mathrm{CE} / \mathrm{SE}$ solutions obtained using a 401 point uniform mesh in $-10 \leq x \leq 10$. 


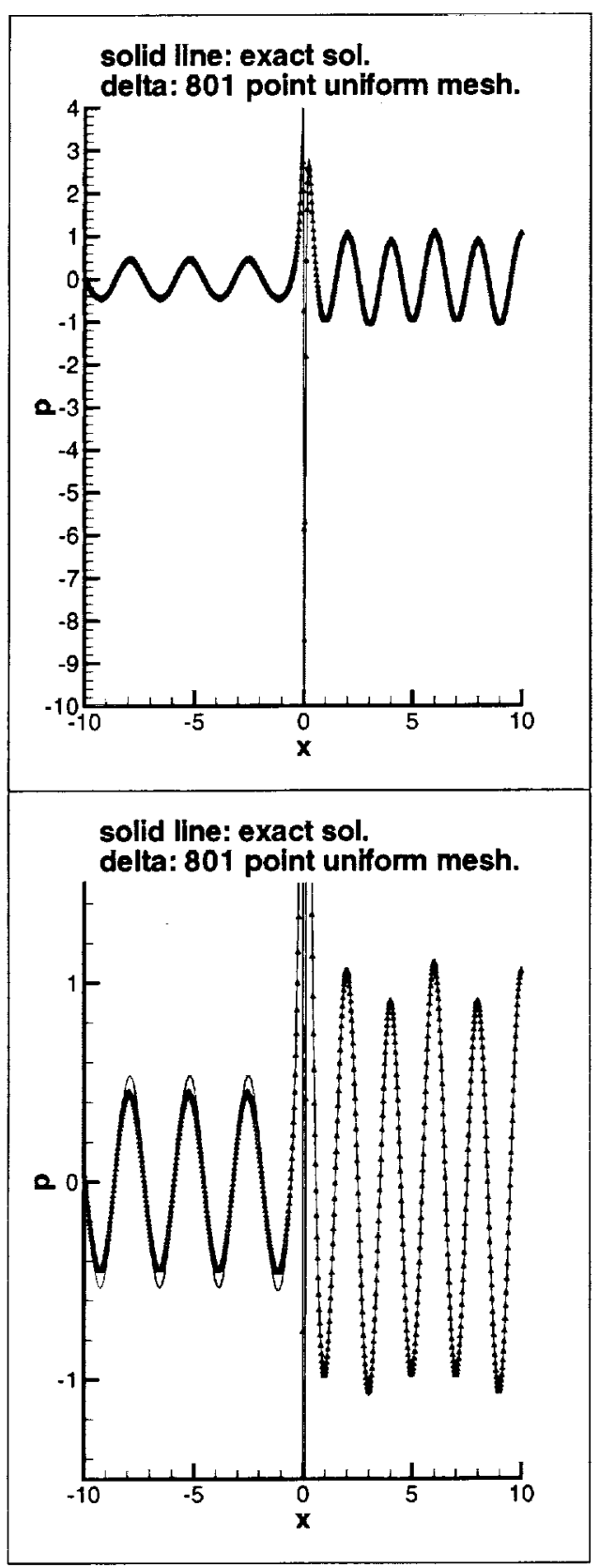

Figure 4: Comparisons between the exact solution and $\mathrm{CE} / \mathrm{SE}$ solutions obtained using an 801 point uniform mesh in $-10 \leq x \leq 10$.

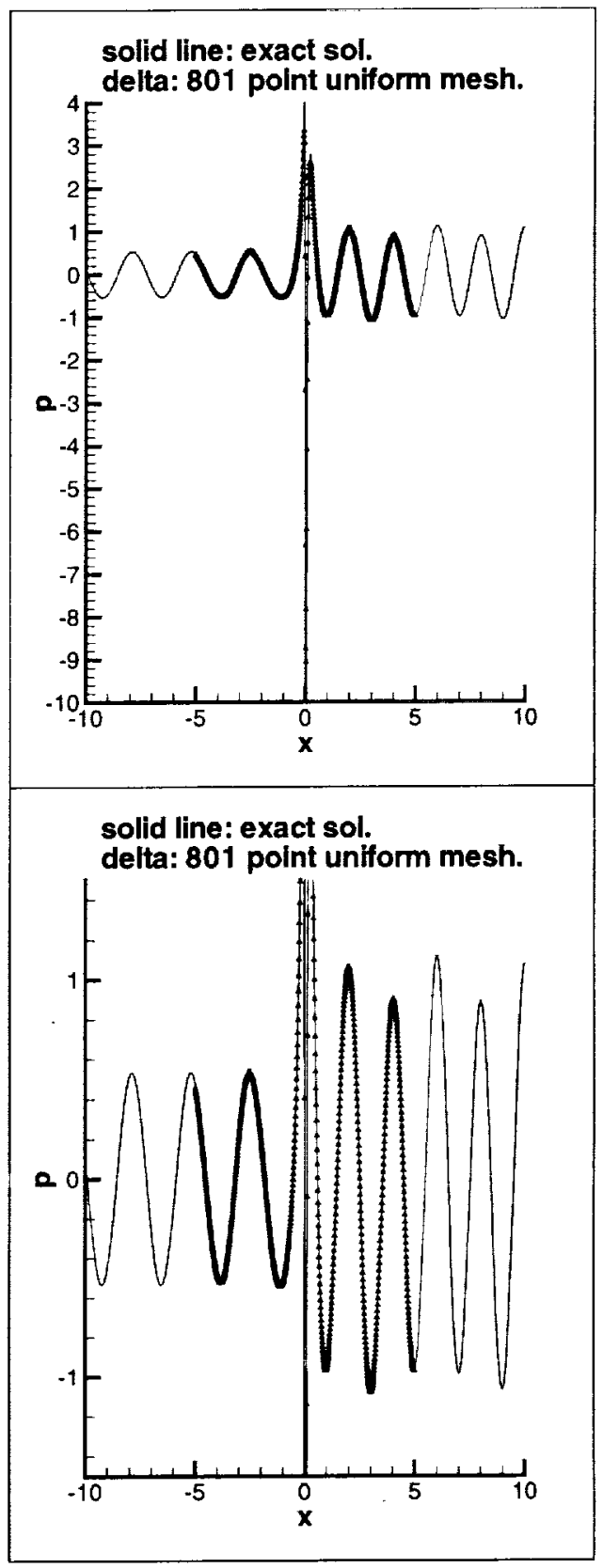

Figure 5: Comparisons between the exact solution and CE/SE solutions obtained using an 801 point uniform mesh in $-5 \leq x \leq 5$. 


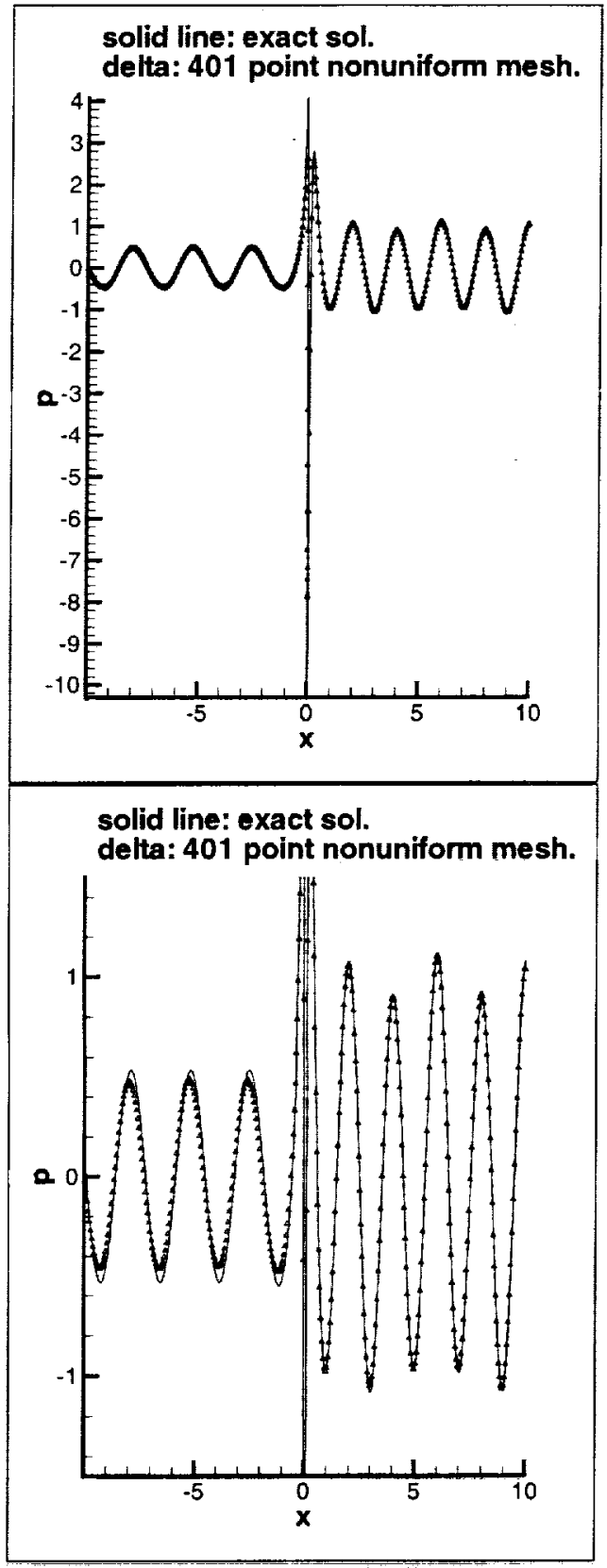

Figure 6: The CE/SE solutions of the acoustic wave $p^{\prime} / \varepsilon$ at $t=20 T$ using a 401 point nonuniform mesh with variable $\epsilon_{j}^{n}$ and $\beta_{j}^{n}\left(\varepsilon=10^{-4}\right)$.

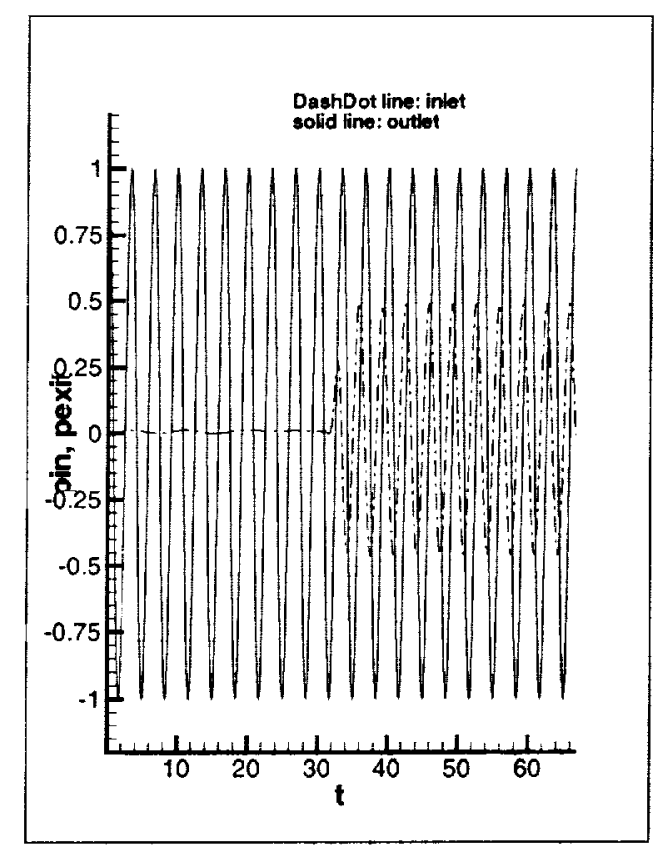

Figure 7: Time history of the acoustic pressure at the inlet and outlet for a stretched 401 point mesh in $-10 \leq x \leq 10$. 


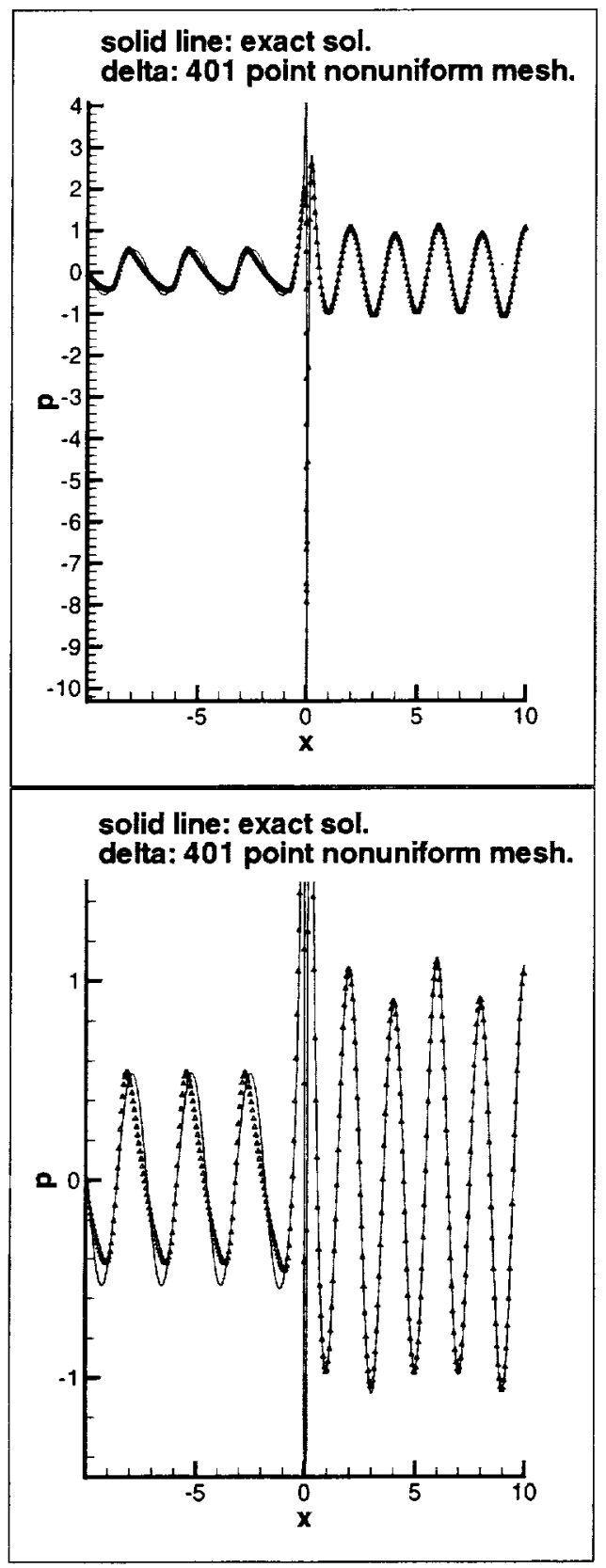

Figure 8: The CE/SE solutions of the acoustic wave $p^{\prime} / \varepsilon$ at $t=20 T$ using a 401 point nonuniform mesh with variable $\epsilon_{j}^{n}$ and $\beta_{j}^{n}\left(\varepsilon=10^{-3}\right)$.

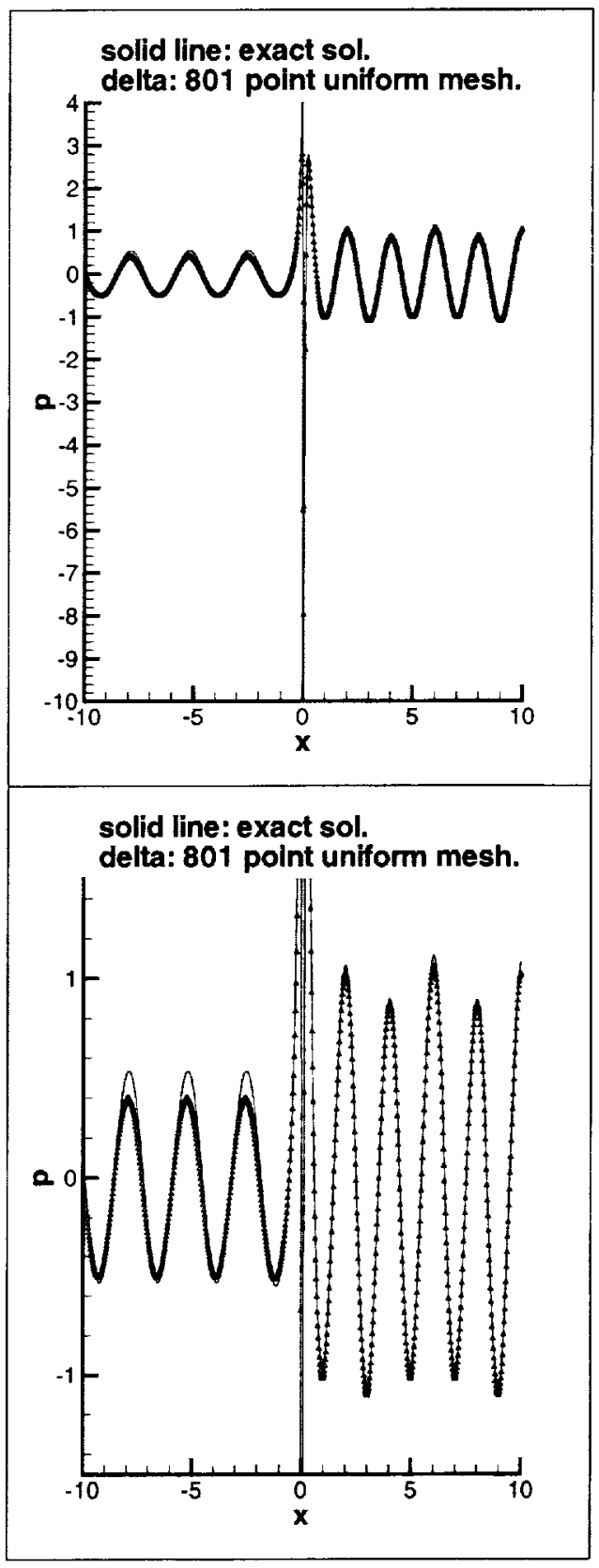

Figure 9: Comparisons between the exact solution and CE/SE linear solutions obtained using an 801 point uniform mesh in $-10 \leq x \leq 10$. 

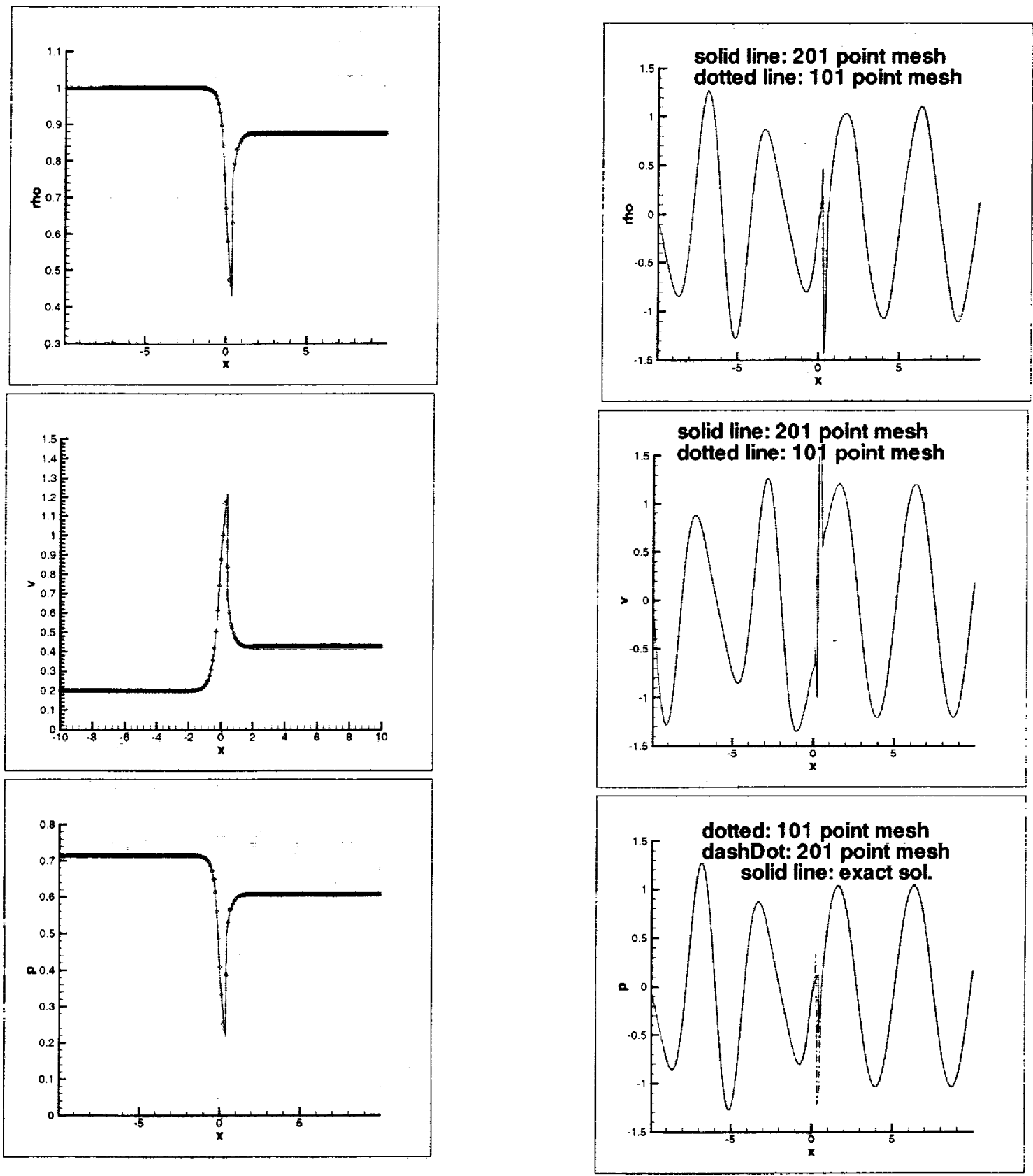

Figure 10: The steady-state $\mathrm{CE} / \mathrm{SE}$ solution(101 point uniform mesh) of the supersonic nozzle flowfield compared with the exact solution represented by solid lines.

Figure 11: The CE/SE nonlinear solutions of the acoustic wave at $t=40 T$ using 101 and 201 point uniform meshes. 


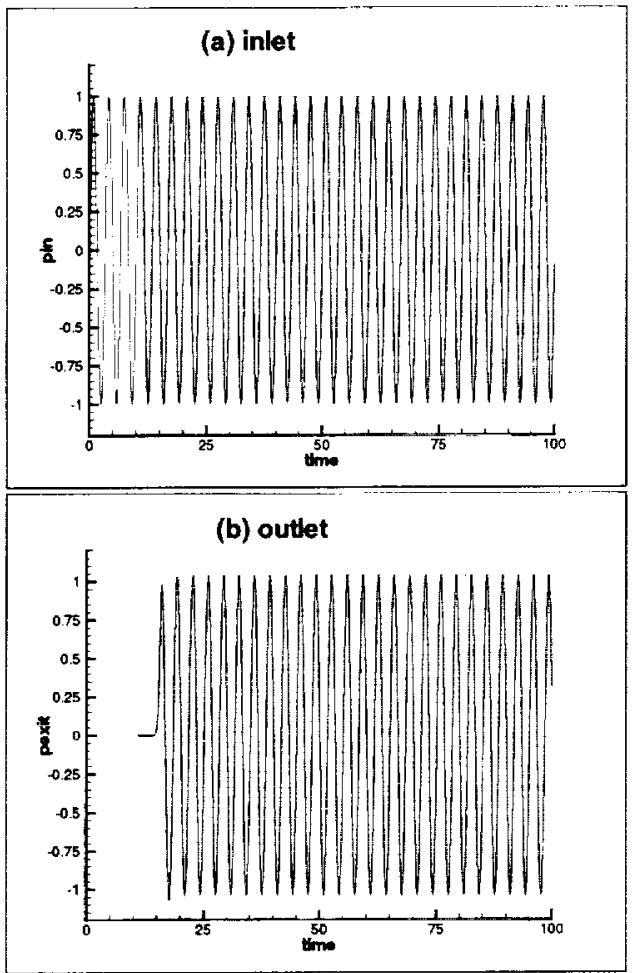

Figure 12: Time history of the acoustic pressure at the inlet and outlet for a 101 point uniform mesh.

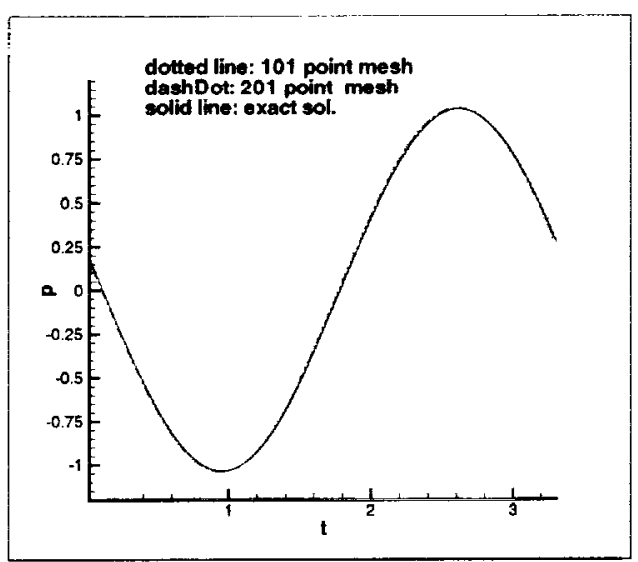

Figure 13: The CE/SE nonlinear solutions of the acoustic wave pressure $p^{\prime}$ at the outlet in one time period for 101 and 201 point uniform meshes.
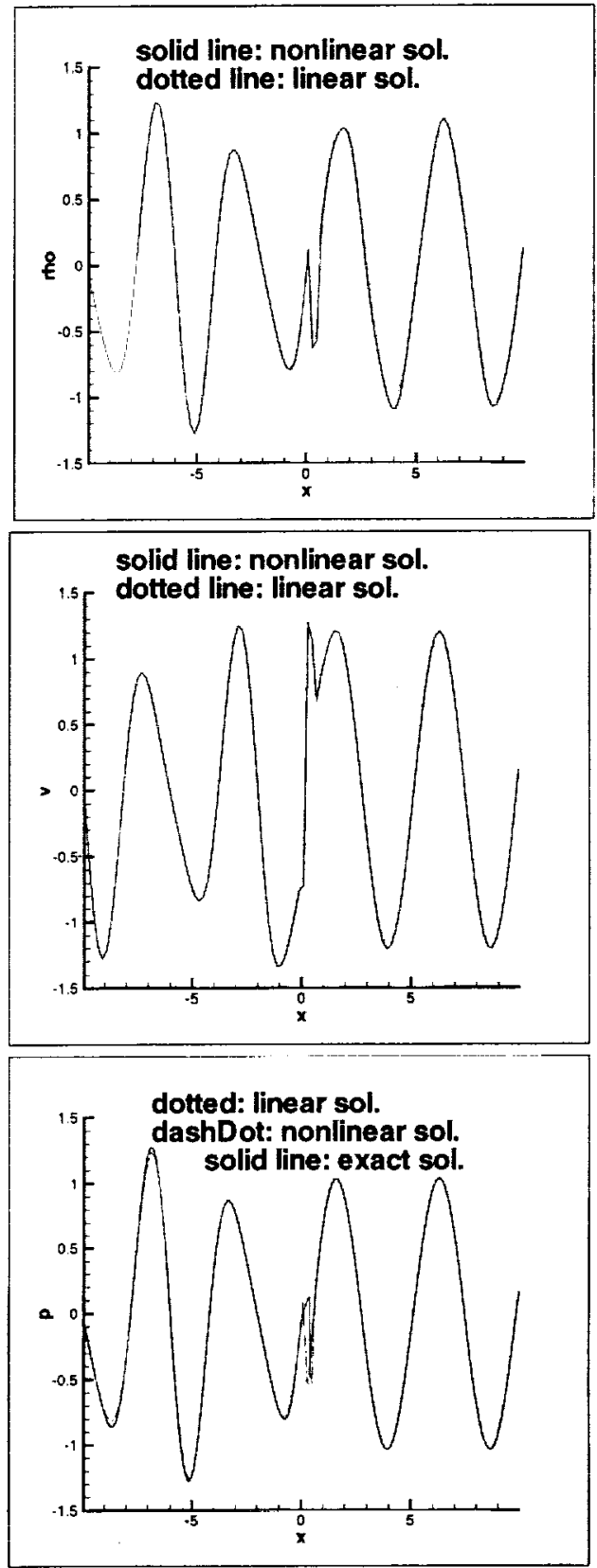

Figure 14: The CE/SE linear solutions of the acoustic wave at $t=40 \mathrm{~T}$ using a 101 point uniform mesh compared with the corresponding nonlinear solution. 
Public reporting burden for this collection of information is estimated to average 1 hour per response, including the time for reviewing instructions, searching existing data sources, gathering and maintaining the data needed, and completing and reviewing the collection of information. Send comments regarding this burden estimate or any other aspect of this collection of information, including suggestions for reducing this burden, to Washington Headquarters Services, Directorate for Intormation Operations and Reports, 1215 Jefferson Davis Highway, Suite 1204, Arlington, VA 22202-4302, and to the Office of Management and Budget. Paperwork Reduction Project (0704-0188), Washington, DC 20503.

\begin{tabular}{|l|l|l}
\hline 1. AGENCY USE ONLY (Leave blank) & $\begin{array}{c}\text { 2. REPOAT DATE } \\
\text { March } 2000\end{array}$ & $\begin{array}{r}\text { 3. REPORT TYPE AND DATES COVERED } \\
\text { Technical Memorandum }\end{array}$
\end{tabular}

\section{TITLE AND SUBTITLE}

Prediction of Sound Waves Propagating Through a Nozzle Without/With a

Shock Wave Using the Space-Time CE/SE Method

6. AUTHOR(S)

Xiao-Yen Wang, Sin-Chung Chang, and Philip C.E. Jorgenson

7. PERFORMING ORGANIZATION NAME(S) AND ADDRESS(ES)

National Aeronautics and Space Administration

John H. Glenn Research Center at Lewis Field

Cleveland, Ohio 44135-3191

9. SPONSORING/MONITORING AGENCY NAME(S) AND ADDRESS(ES)

National Aeronautics and Space Administration

Washington, DC 20546-0001

\section{FUNDING NUMBERS}

WU-523-90-33-00

8. PERFORMING ORGANIZATION REPORT NUMBER

E-12183

10. SPONSORINGMONITORING AGENCY REPORT NUMBER

NASA TM-2000-209937

\section{SUPPLEMENTARY NOTES}

Prepared for the 38th Aerospace Sciences Meeting and Exhibit sponsored by the American Institute of Aeronautics and Astronautics, Reno, Nevada, January 10-13, 2000. Xiao-Yen Wang, Taitech Inc., Cleveland, Ohio 44135; Sin-Chung Chang and Philip C.E. Jorgenson, NASA Glenn Research Center. Responsible person, Philip C.E. Jorgenson, organization code 5880 , (216) 433-5386.

12a. DISTRIBUTION/AVAILABILITY STATEMENT

12b. DISTRIBUTION CODE

Unclassified - Unlimited

Subject Categories: 02 and 71

Distribution: Nonstandard

This publication is available from the NASA Center for AeroSpace Information, (301) $621-0390$

13. ABSTRACT (Maximum 200 words)

The benchmark problems in Category 1 (Internal Propagation) of the third Computational Aeroacoustics (CAA) Workshop sponsored by NASA Glenn Research Center are solved using the space-time conservation element and solution element (CE/SE) method. The first problem addresses the propagation of sound waves through a nearly choked transonic nozzle. The second one concerns shock-sound interaction in a supersonic nozzle. A quasi one-dimension CE/SE Euler solver for a nonuniform mesh is developed and employed to solve both problems. Numerical solutions are compared with the analytical solution for both problems. It is demonstrated that the CE/SE method is capable of solving aeroacoustic problems with/without shock waves in a simple way. Furthermore, the simple nonreflecting boundary condition used in the CE/SE method which is not based on the characteristic theory works very well.

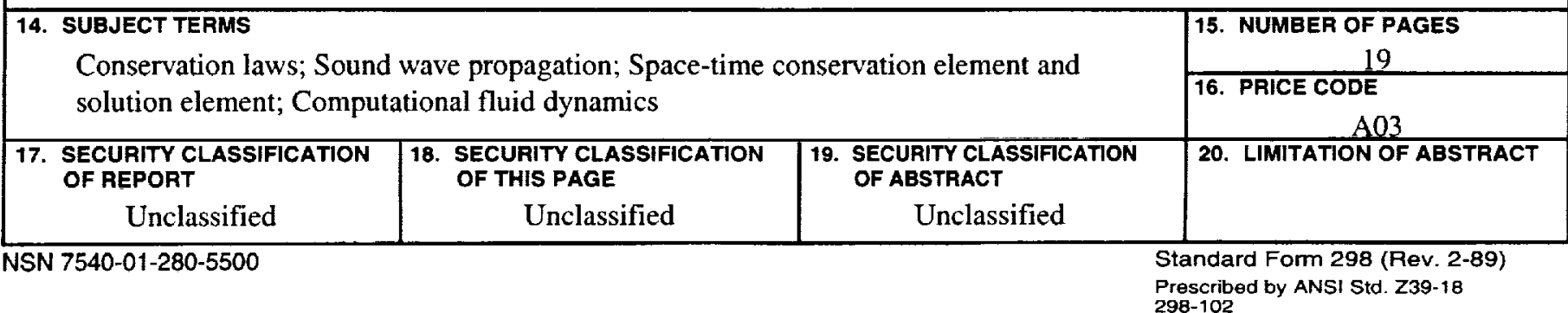

